\title{
PONTOS E CONTRAPONTOS NO UNIVERSO DO ATENDIMENTO EDUCACIONAL ESPECIALIZADO PARA EDUCANDOS COM TRANSTORNO DO ESPECTRO AUTISTA
}

\author{
Marily Oliveira BARBOSA ${ }^{1}$ \\ Neiza de Lourdes Frederico FUMES ${ }^{2}$
}

Resumo: O Atendimento Educacional Especializado (AEE) veio estabelecer novas formas de agir com o público alvo da Educação Especial e, de certa maneira, pretende auxiliar na sua permanência na escola. Em se tratando do educando com Transtorno do Espectro Autista (TEA), a sua entrada na escola regular é relativamente recente e isso desperta situações desafiadoras para todos os envolvidos. O objetivo deste estudo é averiguar o ponto de vista de uma professora do AEE sobre o TEA e os educandos com esse transtorno. Este estudo é de cunho qualitativo por procurar apreender a visão da participante sobre o assunto em questão e utilizou como instrumento para coleta de dados a observação direta, palestra proferida pela pesquisada e a entrevista semiestruturada. Para a análise de dados, foi empregue a análise de conteúdo. Os resultados demonstraram que a professora atendia três educandos com TEA e conhecia os aspectos científicos a respeito do TEA, embora os conhecimentos religiosos também marcassem as suas concepções. A professora relatou os desafios e a satisfação em observar os avanços educacionais de seus educandos, compreendendo inclusive as possibilidades de inclusão destes no ambiente da escola regular.

Palavras-chave: Educação especial. Atendimento educacional especializado. Transtorno do espectro autista.

\section{INTRODUÇÃO}

A nomenclatura Transtorno do Espectro do Autismo (TEA) foi adotada pelo Brasil em 2012, através da Lei 12.764, de 2012, que instituiu a Política Nacional de Proteção dos Direitos da Pessoa com Transtorno do Espectro Autista. Esse termo agrupa em uma única categoria os "autismos" (autismo, síndrome de Asperger e transtorno invasivo do desenvolvimento sem outra especificação) (BRASIL, 2012).

$\mathrm{O}$ ingresso dos educandos com TEA é relativamente recente na escola regular e desperta muitos desafios à escola e aos professores que irão recebê-los (GOMES, 2013).

\footnotetext{
${ }^{1}$ Doutoranda em Educação Especial. UFSCar - Universidade Federal de São Carlos. São Carlos - SPBrasil. 13565-905 - marilyufal@ hotmail.com.

2 Doutora e Docente do Programa de Pós-graduação em Educação. UFAL - Universidade Federal de Alagoas. Maceió - AL - Brasil. 57072-900 - neizaf@uol.com.br.
} 
Para auxiliar na aprendizagem destas crianças (e outras do público-alvo da Educação Especial), com a eliminação de diferentes barreiras, tem sido instituído, pela política pública brasileira, o Atendimento Educacional Especializado (AEE). Esse pode ser "[...] compreendido como o conjunto de atividades, recursos de acessibilidade e pedagógicos organizados institucional e continuamente". (BRASIL, 2011, p.1).

O AEE é um serviço que visa contribuir para a inclusão escolar dos educandos público alvo da Educação Especial e que deve integrar a proposta pedagógica da escola, garantido o acesso, a participação e a aprendizagem destes educandos dentro do ambiente escolar (BRASIL, 2011). Este serviço pode ter um importante papel na permanência do educando com TEA na escola regular, bem como no sucesso de sua aprendizagem.

Estudos, como o de Bridi, Fortes e Bridi Filho (2006) e Gomes (2013), demonstram que este educando é capaz de realizar diversos progressos no ambiente escolar. Dentre outros, destacamos a ampliação de suas interações sociais junto aos colegas de sala e a melhora nas condições cognitivas, inclusive em relação à interpretação de conteúdos mediados pela linguagem e pelo contexto social, representando assim um avanço no processo de inclusão destes educandos.

Diante de tais aspectos, tivemos como objetivo para este estudo compreender o ponto de vista de uma professora do AEE sobre o TEA e os educandos com esse transtorno.

\section{Caminhos metodológicos trilhados}

Esta pesquisa é de natureza qualitativa por buscar entender o significado que as pessoas ou grupo social atribuem a determinados fenômenos, mantendo o foco no significado que os participantes da pesquisa dão a questão, permitindo assim a compreensão de suas respostas de forma a tornar o problema do estudo mais explícito para o pesquisador (CRESWELL, 2010).

Os sujeitos participantes dessa pesquisa foi uma professora do AEE e indiretamente três educandos com TEA por ela atendidos na SRM. Para a coleta de dados, fizemos uso da entrevista semiestruturada definida como um processo de entrevista que consiste em perguntas escolhidas de antemão com o objetivo de extrair informações dos entrevistados, podendo quando necessário acrescentar novas perguntas (ANGROSINO, 2009). Também utilizados para coleta de dados a observação direta dos atendimentos realizados pela professora na escola com os seus 3 alunos com TEA e situações associadas a esse universo, com apoio em diário de campo e videogravações. 
Também tivemos como fonte de dados uma palestra proferida pela professora da pesquisa na escola, durante uma reunião pedagógica com os demais professores da escola.

Como procedimento para coleta dos dados, realizamos um levantamento junto à secretaria de educação municipal de Maceió/Alagoas sobre as escolas que ofereciam o AEE para os alunos com TEA na rede regular de ensino. Destas escolas, encontramos uma que satisfazia os critérios estabelecidos e a direção aceitou a realização da pesquisa.

A partir disso, começamos o processo de coleta de dados na própria escola. As entrevistas (semiestruturada e recorrente), escuta da palestra e as observações com videogravação tiveram a duração de seis meses e foram realizadas conforme disponibilidade de tempo que a professora dispusera para a pesquisa.

Todos os procedimentos para a coleta de dados seguiram estritamente os princípios éticos e a participante assinou o Termo de Consentimento Livre e Esclarecido (TCLE) após ter conhecimento dos objetivos da pesquisa e da forma da sua participação. Foi esclarecido também quanto ao sigilo dos dados coletados e garantido o anonimato. Por conta disto, todos os nomes são fictícios. A pesquisa foi aprovada pelo Comitê de Ética na Pesquisa da Universidade Federal de Alagoas sob o parecer de n ${ }^{\circ}$ 206.411/2013.

Posteriormente à coleta dos dados, realizamos uma leitura minuciosa e exaustiva dos materiais produzidos e dessa leitura e de outros procedimentos descritos pela análise de conteúdo emergiram categorias de análise. Minayo (2004, p.209) menciona que este tipo de análise “[...] consiste em descobrir os núcleos de sentido que compõem uma comunicação cuja presença ou frequência signifiquem alguma coisa para o objeto analítico visado". A análise desdobra-se em três etapas: pré-análise; exploração do material e tratamento dos resultados obtidos e interpretação. Vejamos a seguir as discussões elencadas para a discussão dos dados.

\section{Resultados e análise dos dados}

Os sujeitos da pesquisa foram uma professora do AEE e três educandos com TEA. A professora Diana cursou graduação em Direito e em Letras. Em relação a cursos de pós-graduação, era especialista em Psicopedagogia e em Atendimento Educacional Especializado. Diana possuía quatro anos de atuação no AEE e sempre trabalhou na mesma escola da pesquisa. Além desse emprego, Diana trabalhava como psicopedagoga em clínica particular havia 12 anos, inclusive atendendo educandos com TEA, embora nos casos mais graves, ela relatou encaminhar para uma colega de profissão. 
Os três educandos com TEA aqui chamados de Nicolas, Joaquim e Gilvan em 2013, ano da coleta de dados, estavam regularmente matriculados no Ensino Municipal, em diferentes níveis de ensino, respectivamente na série do $1^{\circ}, 2^{\circ}$ e $3^{\circ}$ ano do Ensino Fundamental. Todos frequentavam o AEE duas vezes por semana com a professora da pesquisa. Joaquim e Gilvan possuíam auxiliar de sala, conforme atendimento prescrito (BRASIL, 2013).

Com a professora, buscamos identificar sua visão sobre o TEA, visto que acreditamos que a forma como a professora concebe e compreende seus educandos interfere de forma direta em sua ação (CUNHA, 2010).

A análise dos dados revelou que Diana parecia ter duas concepções fundamentais sobre o TEA, que, embora sejam antagônicas, conviviam uma com a outra: uma sobrenatural e outra científica. Comecemos por sua concepção, fundamentada na ciência médica:

Como um transtorno global do desenvolvimento (risos), porque não tem definição do autista. Tem sim características. Ela tem ecolalia, ela está com seis anos e ainda se trata como terceira pessoa. Ela repete frases formadas de um desenho animado. [...] o autismo tem vários graus. É muito incógnito o desenvolvimento da criança com autismo. (Entrevista semiestruturada, 2012).

A professora Diana relatou algumas características do TEA, como por exemplo, a inversão prenominal e a ecolalia, descritas por diversos autores que se fundamentam na visão médica, inclusive citou que cada indivíduo com TEA possui características próprias e aspectos únicos relacionados à sua condição no espectro (CUNHA, 2010; GOMES, 2013; AMERICAN PSYCHIATRIC ASSOCIATION, 2013). Diante disto, percebemos o quanto as posições da professora se aproximam com o que é apontado pela literatura científica, principalmente o exposto pela área médica.

A própria noção de TEA é uma categoria construída através da observação das peculiaridades dos sujeitos. Assim, ninguém busca refletir sobre o que há por trás destes diagnósticos e quais as suas implicações. Sobre isso, Vasques (2008) considera que este modelo de diagnóstico possui limitações, visto que não analisa, nem registra as variações qualitativas dos comportamentos expostas acima, abnegando inclusive as características do contínuo presente no TEA.

Ainda na fala da professora observamos os aspectos singulares do TEA e sua relação com cada indivíduo que o possui. Diana salientava a não existência de regras ou 
fórmulas para lidar com estes educandos e esta ideia é também manifesta por muitos professores que apontam para a não existência de forma única de como trabalhar e ensinar (CUNHA, 2010).

Outra visão sobre o TEA que a professora possuía dizia respeito a concepção sobrenatural, expostas em diferentes momentos:

Eu definiria como uma doença da alma, um transtorno da alma porque existe algum motivo daquela criança estar vivendo em outro mundo, né? [...] Em minha opinião, é um transtorno da alma. (Entrevista semiestruturada, 2012).

Não é a questão de: '-Ah, é um carma, ah é isso!'. Não, nesse lado é que eu acho assim que cada ser humano tem uma função e às vezes a gente se depara com alguma situação que no fundo veio pra ensinar, $e$, eu acho que o autista, as crianças com necessidades especiais, elas, a gente percebe que elas têm muito desse contexto. Muitas vezes, ela vem de uma família muito tradicional, muito certinha, que precisa se desestruturar. Outras vezes, a gente vê uma criança com necessidade especial na família muito preconceituosa, então eu acho que vem pra ensinar alguma coisa. Tem uma função aqui na terra, não está passando de férias. (Entrevista Recorrente, 2013).

A professora demonstrou a partir do seu discurso a questão do TEA relacionar-se com a espiritualidade/religiosidade, inclusive sobre os aspectos sobrenaturais. Quando os estudos sobre o TEA iniciaram, estudiosos, como Kanner (1997) cogitaram a ideia de que a causa para este transtorno estivesse associada a algo além das origens genéticas e inatas. No entanto, essa ideia atualmente é vista como equivocada por estudiosos da área, ainda que encontremos na atualidade resquícios da ideia de que o TEA esteja interligado a outras causas que não as de ordem científica (RIVIÉRE, 2010).

Essa persistência de concepções fundadas na religião e no sobrenatural permanecia na subjetividade da professora Diana, ainda que ela possuísse dois cursos de especialização lato sensu e atuasse diariamente com educandos com TEA. Ao ser indagada sobre o transtorno, demonstrou permanecer com sentidos balizados por concepções do senso comum, não científicas, demonstrando que as diversas formações acadêmicas não foram capazes de modificar completamente as suas concepções sobre o TEA.

De fato, o TEA ainda não possui uma causa específica, como afirma Gomes (2013). Todavia, acreditar com sendo algo "espiritual" ou "sobrenatural" denota uma descrença nos conteúdos científicos abordados nas diversas formações. Vasques (2008, 
p.176) argumenta que "[...] o professor pode oferecer outras interpretações para seu educando, interrogando sentidos que, muitas vezes, cristalizam-se em função dos diagnósticos, classificações, avaliações etc.”. Suas posições levam-nos a indagar sobre a forma que a professora concebia os educandos com TEA: se como alguém padecendo de algo ou como um indivíduo que possui algumas particularidades, mas que se beneficia da escola como todos os outros? A visão de Diana apontava para a possibilidade de aprendizagem, expressando também fundamentos da educação inclusiva:

Essa criança com autismo, por exemplo, ela entrou no primeiro ano, ela tem de evoluir até o final. Ele pode não evoluir igual à turma. Ela entrou fazendo isso, ela vai sair fazendo isso mais aquilo. Então, a partir do momento que a gente bota a inclusão na cabeça. Que tem de existir uma evolução, em todos os aspectos, no aspecto pedagógico, no aspecto social, no aspecto de autonomia, porque a gente tem de ver o aluno com necessidade especial. Eu sempre boto na cabeça, eu tenho que pensar nesse aluno adulto, então meu foco é na autonomia dele, dentro e fora da escola. (Entrevista semiestruturada, 2012).

Nessa perspectiva, independente da criança se enquadrar no TEA, ela tem os mesmos direitos que todos os cidadãos, inclusive de frequentar e permanecer na mesma escola como fundamentado em diversos documentos legais (BRASIL, 1996, 2011).

Desta feita, é indispensável que o professor conheça as características de seu educando, bem como as dificuldades que ele possua, pois assim poderá planejar ações e atividades que contribuam na minimização das dificuldades resultantes dos déficit de sua condição. O AEE para o educando com TEA tem o objetivo de complementar o ensino, bem como de auxiliar no desenvolvimento e aprendizagem como um todo (BRASIL, 2011).

Após a professora expor seu ponto de vista sobre o TEA, perguntamos sobre as crianças atendidas por ela que possuíam o transtorno. Imediatamente, ela mencionou que tinha três educandos: Nicolas, Joaquim e Gilvan. Os dois primeiros possuíam diagnóstico de TEA e o terceiro tinha deficiência intelectual (Síndrome de Down), com suspeita de TEA. Tais diagnósticos foram realizados por profissionais da área médica e mencionados por Diana na ocasião da palestra.

Durante a entrevista semiestruturada, a palestra e no início das observações dos atendimentos em si, a professora relatava que os três educandos tinham TEA, inclusive por ocasião de atendimento, a cuidadora perguntou sobre as dificuldades da fala de Gilvan e a professora respondeu que seria devido ao TEA: 
Durante a atividade dele [Gilvan], a auxiliar perguntou se o problema da fala era por causa da síndrome e a Diana respondeu que não era por conta da Síndrome de Down, mas provavelmente por causa do autismo. Disse neste momento que já pediu que a mãe levasse para ser diagnosticado e nada. (Diário de campo 20/03/2013).

De fato, no Brasil o diagnóstico do TEA é eminentemente clínico e se dá através de profissionais da área da saúde, como médicos psiquiatras e neuropsiquiatras seguindo critérios diagnósticos presentes no DSM V (AMERICAN PSYCHIATRIC ASSOCIATION, 2013), com apoio na CID-10 (2000) (GOMES, 2013).

Em pesquisa recente, Fumes e Moraes (2014) observaram que ainda há ênfase ao diagnóstico clínico na cidade de Maceió, entretanto a entrada do educando para o AEE não mais está condicionado a ele. Atualmente, há outros procedimentos que buscam definir o encaminhamento do educando para o AEE, podendo ser feita pela demanda do professor da sala de aula para o do AEE. São realizadas observações, avaliação psicopedagógica e/ou anamnese (BRIDI, 2012; BRASIL, 2014; FUMES; MORAES, 2014).

$\mathrm{Na}$ entrevista recorrente, a professora falou sobre os três educandos como sendo educandos com TEA e sobre o educando Gilvan mencionou algumas de suas dúvidas:

\begin{abstract}
O Gilvan é [...] $O$ Gilvan ainda não tem definição. Eu pedi uma reavaliação dele agora, mas estão [familiares] tentando marcar uma reavaliação [...] Não é que ele tenha, ele funciona, em alguns momentos, como uma criança autista, mas que isso não possa ser o autismo, possa ser uma outra síndrome que a gente ainda não sabe o que é que é. (Entrevista Recorrente, 2013).
\end{abstract}

O recorte anterior mostra que a professora Diana tinha dúvidas a respeito do diagnóstico do educando Gilvan: síndrome de Down, autismo, outra síndrome qualquer. No laudo médico do educando, estava posto que ele possuía síndrome de Down com suspeita de TEA (Diário de campo, 20/03/2013). Nas falas de Diana era recorrente a necessidade de enquadramento do educando em alguma categoria do público alvo da educação especial. Segundo a professora, era a partir dessas características que ela planejava o AEE e realizava as adequações necessárias para a efetiva inclusão escolar do educando.

No particular do educando Gilvan, cabe salientar que no início da pesquisa, Diana assegurava que ele tinha o TEA e como consequência disso, estimulava que as auxiliares 
de sala e professora da sala de aula comum participassem das palestras e da formação da SEMED sobre como lidar com crianças com TEA, como também toda a escola foi trabalhada sobre lidar com esse educando a partir das características do transtorno.

Passados dois meses, a sua posição começou a ser modificada. Em diversos momentos de observação, Diana mencionou não saber sobre o diagnóstico e também relatava suas dificuldades em lidar com o Gilvan. Bridi (2012) menciona que muitas professoras necessitam agrupar o educando em alguma especificidade do público alvo da educação especial, para assim realizar o serviço do AEE e enquadra-lo no Censo Escolar.

Sobre o educando Gilvan, ele era assíduo na escola, tinha dificuldade em permanecer na sala de aula. A todo o momento, o educando estava acompanhado por sua cuidadora. No AEE, tinha dificuldades em realizar o solicitado por não conseguir permanecer sentado e perseverar nas atividades, nos poucos momentos que as fazia era quando a professora trazia algo de seu agrado, como por exemplo, os personagens infantis. Sobre o AEE para este educando, a Diana relatou: “O Gilvan é uma criatura que eu não sei como seguir. Eu não consigo que ele fique 15 minutos na sala, mas eu tenho que conseguir algo”. (Diário de campo - 22/05/2013).

Após esse dia (22/05/2013) e em ocasião de conversa entre os atendimentos, a professora relatou que o educando Gilvan devia ter a Síndrome de Down e alguma outra síndrome que teria de ser investigado e não mais se enquadrava como TEA. A professora não mais enxergava o educando Gilvan como pertencente à categoria de TEA. A partir desta mudança de posição, o educando Gilvan não mais integrou os grupos de educandos com TEA. É importante expor que Gilvan continuou sendo atendido no AEE pela mesma professora, embora que em outro dia que não era observado por este estudo.

Esses fatos levam-nos a refletir sobre a atuação do professor em geral e nas consequências que as suas concepções tem para a vida escolar do educando. No caso em análise, em 2012 e início de 2013, Diana afirmava que Gilvan era autista e, desse modo, a escola, a cuidadora e seus colegas de sala o tratavam como tal. Contudo, com a mudança de enquadramento da professora, também mudou a sua atuação com o educando e as suas orientações para a comunidade escolar.

Tais aspectos sobre o Gilvan foram expostos para refletirmos sobre a importância da professora do AEE na família e na comunidade escolar ao qual o educando faz parte. Esse modelo de atendimento brasileiro atual está centralizando nesse profissional, as decisões sobre a trajetória escolar do educando do público alvo da Educação Especial, pelo fato da comunidade acreditar que ele possui os conhecimentos necessários para isso. 
Sendo assim, é necessário repensar o tipo de formação que estes profissionais recebem, visto a gama de responsabilidades que ele possui.

\section{Considerações finais}

A escola é um espaço privilegiado para a troca de conhecimentos a partir das vivências e diferentes ações existentes dentro dela. Ao se falar de inclusão escolar partimos do pressuposto de que a escola deve possuir ações que possam contribuir para a inclusão de todos, relacionados ao acesso, permanência e aprendizagem. $\mathrm{O}$ acesso é previsto por lei, inclusive existem penalidades para as escolas que recusarem o acesso dos educandos ao seu ambiente (BRASIL, 1988, 1996, 2012). A permanência diz respeito a diversas ações a serem executadas no ambiente escolar, sendo estas: acessibilidade, qualificação dos professores e comunidade escolar, conscientização, bem como aprendizagem com qualidade aos conteúdos escolares. E o terceiro diz respeito ao aprendizado dos conteúdos escolares. A inclusão escolar só acontece quando este tripé existe para todos os educandos.

A partir do que nos foi permitido observar, a professora tinha diversos pontos de vista sobre o TEA, demonstrando inclusive sua necessidade em enquadrar o educando na categoria de TEA, por isso buscava incansavelmente o diagnóstico médico alegando a necessidade deste para trabalhar de forma a diminuir o déficit advindo do transtorno, entretanto o AEE realizado pela professora Diana para estes educandos não possuía características, nem uma prática voltada para as dificuldades das áreas relacionadas à tríade do TEA: comprometimento qualitativo na interação social, linguagem e movimentos restritivos, repetitivos e estereotipados.

O AEE deve auxiliar o educando a se desenvolver nas suas necessidades individuais, derrubando barreiras que dificultam seu processo aprendizagem nos contextos educacionais. Tais aspectos só poderão ser alcançados quando o AEE exercer seu papel e para isso há a necessidade da realização do AEE de forma individualizada para cada educando.

Tais aspectos levam-nos a ponderar sobre as questões positivas existentes no AEE. Vale ressaltar que há a necessidade de novas pesquisas e ampliação do conhecimento acerca da atividade docente dos professores do AEE, visto que esta função é relativamente recente e desperta em todos a necessidade da ampliação do conhecimento relacionados à atividade em si. 


\section{POINTS AND COUNTERPOINTS IN THE UNIVERSE OF SPECIALIZED EDUCATIONAL SERVICE FOR STUDENTS WITH AUTISM SPECTRUM DISORDER}

Abstract: The Educational Service Specialist (ESA) established new ways of doing things with the target audience of Special Education and, in a way, intends to help her stay in school. In the case of the students with Autism Spectrum Disorder (ASD), their entry is relatively recent in the Brazilian schools and this awakens challenging situations for all. The aim of this study was to ascertain the views of ESA's teacher about the TEA and the students with this disorder. This study used a qualitative approach by seeking to grasp the vision of participant about the issue and it was used as a tool for data collection the direct observation, a lecture of ESA teacher and a semistructured interview. For data analysis, it relied on the content analysis. The results showed that the teacher met three students with ASD and knew the scientific aspects regarding the TEA, although the religious knowledge also to mark their designs. The teacher reported the challenges and satisfaction in observing the educational progress of their students, including understanding the inclusion of these possibilities in the regular school environment.

Key words: Special education. Educational service specialist. Autism spectrum disorder.

\section{REFERÊNCIAS}

ANGROSINO, M. Etnografia e observação participante. Porto Alegre: ARTMED, 2009.

AMERICAN PSYCHIATRIC ASSOCIATION. Autism Spectrum Disorder. Washington, DC: APA, 2013. Disponível em: <http://www.dsm5.org/Pages/Default.aspx>. Acesso em: 15 jul. 2013.

BRASIL. Constituição (1988). Constituição da República Federativa do Brasil: promulgada em 5 de outubro de 1988. Brasília: Imprensa Oficial, 1988.

Ministério da Educação. Decreto no $\mathbf{7 . 6 1 1}$, de 17 de novembro de 2011. Dispõe sobre a educação especial, o atendimento educacional especializado e dá outras providências. Brasília: FNDE, 2011.

Lei $\mathrm{n}^{\circ}$ 12.764, de 27 de dezembro de 2012. Institui a Política Nacional de Proteção dos Direitos da Pessoa com Transtorno do Espectro Autista. Diário Oficial da União: República Federativa do Brasil, Brasília, DF, 28 dez. 2012.

Lei de Diretrizes e Bases da Educação Nacional, LDB 9.394, de 20 de dezembro de 1996. Brasília: MEC, 1996. 
Nota técnica $n^{\circ} 04$ - Orientação quanto a documentos comprobatórios de alunos com deficiência, transtornos globais do desenvolvimento e altas habilidades/superdotação no Censo Escolar. Brasília: MEC / SECADI / DPEE, 2014.

. Nota técnica no 24 / 2013 MEC / SECADI / DPEE. Orientação aos sistemas de ensino para a implementação da Lei no 12.764/2012. Brasília: MEC, 2013.

BRIDI, F. R. S. Avaliação inicial no atendimento educacional especializado: dilemas e consequências. Revista Educação Especial, Santa Maria, v.25, n.44, p.499-512, set./dez. 2012.

; FORTES, C. C.; BRIDI FILHO, C. A. Educação e autismo: as sutilezas e as possibilidades do processo inclusivo. In: ROTH, B. W. Experiências educacionais inclusivas: Programa Educação Inclusiva: direito à diversidade. Brasília: Ministério da Educação, Secretaria de Educação Especial, 2006. p.63-74.

CRESWELL, J. W. Projeto de pesquisa: métodos qualitativo, quantitativo e misto. Tradução de M. Lopes. 3.ed. Porto Alegre: ARTMED, 2010.

CUNHA, E. Autismo e inclusão: psicopedagogia práticas educativas na escola e na família. 2.ed. Rio de Janeiro: Wak Ed., 2010.

FUMES, N. L. F.; MORAES, W. D. S. A avaliação das necessidades educacionais do (a) aluno (a) das salas de recursos multifuncionais das escolas municipais de Maceió/ Alagoas. Relatório parcial do Programa Institucional de Bolsas de Iniciação Científica (PIBIC). Maceió: Universidade Federal de Alagoas, 2014.

GOMES, C. G. S. Aprendizagem relacional, comportamento simbólico e ensino de leitura a pessoas com transtornos do espectro do autismo. 2013. $176 \mathrm{f}$. Tese (Doutorado em Psicologia) - Universidade Federal de São Carlos, São Carlos, 2013.

KANNER, L. Os distúrbios do contato afetivo. In: ROCHA, P. S. (Org.). Autismos. São Paulo: Escuta, 1997. p.111-170.

MINAYO, M. O desafio do conhecimento: pesquisa qualitativa em saúde. 8.ed. São Paulo: Hucitec-Abrasco, 2004.

RIVIÉRE, A. O autismo e os transtornos globais do desenvolvimento. In: COLL, C.; MARCHESI, A.; PALACIOS, J. (Org.). Desenvolvimento psicológico e educação. Transtornos do desenvolvimento e necessidades educativas especiais. 2.ed. Porto Alegre: ARTMED, 2010. p.234-256. 3v.

VASQUES, C. K. Alice na biblioteca mágica: uma leitura sobre o diagnóstico e a escolarização de crianças com autismo e psicose infantil. 2008. 195 f. Tese (Doutorado em Educação) - Faculdade de Educação, Universidade Federal do Rio Grande do Sul, Porto Alegre, 2008. 